Sādhanā Vol. 28, Part 5, October 2003, pp. 915-924. @ Printed in India

\title{
Ductile streaks in precision grinding of hard and brittle materials
}

\author{
V C VENKATESH, S IZMAN, S SHARIF, T T MON and M KONNEH \\ Department of Manufacturing \& Industrial Engineering, Faculty of Mechanical \\ Engineering, Universiti Teknologi Malaysia, UTM Skudai, Malaysia \\ e-mail:venkates@fkm.utm.my
}

\begin{abstract}
Ductile streaks produced during diamond grinding of hard and brittle materials have aided the subsequent process of polishing. Two novel techniques were used to study the formation of ductile mode streaks during diamond grinding (primary process) of germanium, silicon, and glass. In the first technique, aspheric surfaces were generated on $\mathrm{Ge}$ and $\mathrm{Si}$ at conventional speeds $(5000 \mathrm{rpm})$. In the second technique, diamond grinding of plano surfaces on glass and $\mathrm{Si}$ surfaces using high speed $(100,000 \mathrm{rpm})$ was carried out. Form accuracy, surface finish and ductile mode grinding streaks are discussed in this paper. It was found that resinoid diamond wheels gave more ductile streaks than metal-bonded wheels but better form accuracy was obtained with the latter. Ductile streaks were obtained more easily with pyrex rather than with BK 7 glass thus necessitating very little time for polishing. Ductile streaks appeared in abundance on germanium rather than silicon. Both the novel grinding techniques were used on CNC machining centres.
\end{abstract}

Keywords. Aspheric and plano grinding; ductile streaks; polishing; Ge; Si and glass; surface integrity.

\section{Introduction}

Traditional methods of generating aspheric surfaces on glass have been time consuming (Horne 1984). A novel technique was developed by Van Ligten and Venkatesh which brought about heavy material removal without affecting surface finish and profile (Van Ligten \& Venkatesh 1985, 1986). The authors were able to obtain surfaces which satisfied ophthalmic conditions, but not those expected of precision optics. This technique was extended to germanium and silicon using both metal bonded and resinoid bonded wheels.

The second technique involving plano surfaces was used on glass and silicon on a set-up similar to high speed jig grinding. Resinoid and electroplated diamond wheels were used to produce ductile streaks on glass and silicon. Surface finish, form accuracy, and smoothness were analysed on a Form Talysurf, while surface integrity was studied on scanning electron, atomic force and optical microscopes. Micrographs of ground surfaces show material removal both by ductile grinding and by fracture. These results are discussed in this paper. 


\section{The machining method and set-up}

\subsection{Aspheric generation (Venkatesh \& Tan 1990)}

To remove material quickly and end up with the desired surface, the contact area between the grinding tool and the work piece should be as large as possible. Since only spheres and toroids permit the condition of full area contact, partial area contact, or line contact will be the best alternative. The use of a machine with a rotating tool suggests that the contact surface must be symmetrically rotational. In general, the shape of the work piece is not predictable, hence, the condition of the large contact area is put in jeopardy. Thus, the method was chosen based on a long line contact between the tool and the work piece during the first step of rough grinding. During the subsequent steps of polishing, the use of a flexible tool allows conformity between the work piece and the tool, approaching the original condition of a contact area.

Two cup-shaped identical size diamond-grinding wheels with metallic (D20/30 MICL50M-1/4) and resinoid (SD240-R1OO B69-6 mm) bonding were used. The profile of the grinding edge is circular in this case, but not restricted to this shape, thus, forming a toroid. The important feature is that the grinding surface shape is axially symmetrical. It is now possible to program the tool path of this tool on the CNC-machine such that it is in line (or arc) contact with the work piece as it cuts the desired shape on the glass.

To illustrate this, the grinding of a paraboloid is shown. The cup tool can be thought of as consisting of a collection of circles whose planes are perpendicular to the axis of rotation of the tool. When the paraboloid is intersected by a plane, as shown in figure 1, the common line is an ellipse. When the task is to cut a concave paraboloid, the tool must fit inside the paraboloid. Hence, the tool must have a diameter smaller than the shortest radius found on the ellipse of intersection of any plane intersecting the paraboloid. In the case of a paraboloid, the shortest radius of curvature on the eclipse of intersection is found when the plane contains the axis of symmetry of the paraboloid.

Any circle at the outer side of the tool can be contained in one of the planes intersecting the paraboloid. The angle that this plane makes with the axis of the parabolid can be adjusted such that the arc of the circle and that of the ellipse (figure 1b) at d, differs in sag height no more than a preset tolerance. This condition sets a certain common arc length over which the difference in sag does not exceed a certain value, say 0.5 micrometers. Now the work piece can be rotated around line 1 in figure 1a. After completion of one revolution, the surface left on the glass work piece will be a zone of the paraboloid, as indicated in figure 1a. Subsequently, the tool axis can be programmed to take a slightly different position relative to the axis of

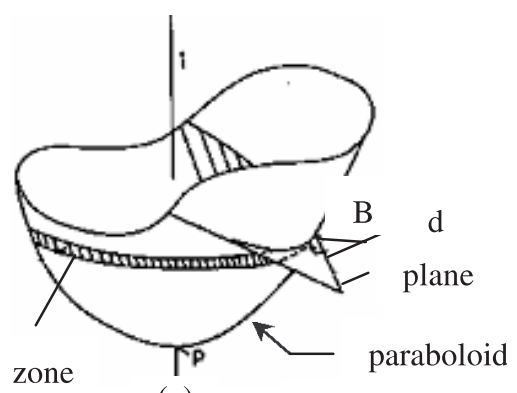

(a)

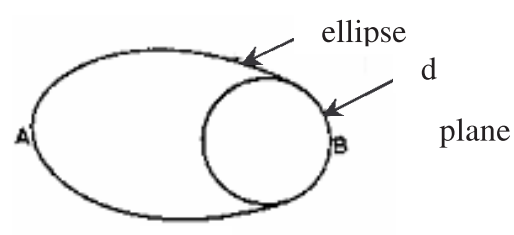

(b)

Figure 1. A plane intersecting a paraboloid (a), in an ellipse (b). 
rotation of the work piece, as well as relative to the apex $P$, of the paraboloid. The sequence is then repeated to form a neighbouring zone of the one indicated in figure 1a.

Two 5-axis vertical CNC machining centres (Fadal and Deckel) are programmed to perform these sequences continuously, until the paraboloid is completed. In this manner, a zone is ground during one revolution. While in cutting with a point tool, in principle one line of the paraboloid is cut It is, thus, clear that this method of grinding with the nearest arc-contact, can complete the same surface faster than in the case of cutting with a point-tool.

The thermal imaging materials used were monocrystalline germanium and silicon. Both blanks were polished after grinding. A special aluminium tool was developed. A felt cloth was glued to the spherical surface of this tool and a polishing paste of one micron alpha alumina was applied to it during polishing. The same set-up was used for polishing on the CNC machine.

\subsection{Plano grinding (Venkatesh et al 2002)}

The objective here is to grind plano (flat) surfaces, with the areas being quite small $(10 \times$ $12 \mathrm{~mm}^{2}$ ). Very high quality $\mathrm{Si}$ as thin as $1 \mathrm{~mm}$ (wafer) and as thick as $10 \mathrm{~mm}$ (lenses) and optical glass (BK7 and Pyrex) were used. An air-powered jig grinding unit (NSK Planet 1500) was attached to the vertical spindle of a MAHO CNC milling machine to provide tool path movement in plano grinding. One advantage of using an air-driven low powered jig grinder is that it stalls when cutting forces exceed 10 newtons. The operating pressure of the Planet was set constant to $4 \mathrm{~kg} / \mathrm{cm}^{2}$ throughout the experiment. The uneven cut surface on BK7 Schott glass work piece that produced after diamond sawing was flattened prior to plano grinding using a resinoid cup wheel (SDC230 P100BW4-6). For rough grinding (flattening) and fine grinding operations the same grinding tool (grinding pin) was used for wafer applications and separately for the lens operation to avoid heat accumulation in the former application. For both work pieces, resinoid-bonded mounted wheels (1A1W-5-6-1·5/D64-D91-D126/C100) also known as grinding pins because of their size $(\phi 5 \mathrm{~mm})$ were used as grinding wheels. Special fixtures were designed to hold different work piece geometry and at the same time to provide rigidity during grinding. For both materials, rough and plano grinding were carried out in a single setting without removing the work piece from the fixture so that the flatness could be maintained. Close-loop coolant system complete with filtering unit was fabricated to ensure that only clean coolant was supplied continuously to the work piece during grinding. Castrol Miracol 80 coolant with ratio 1:50 was used.

Figure 2 shows this experimental set-up. Three different feed rates $(5,20$ and $35 \mathrm{~mm} / \mathrm{min})$ and three depths of cut $(5,15$ and $25 \mu \mathrm{m}$ ) were used to grind silicon and BK7 glass (with additional feeds of $2.5,17.5$ and $32.5 \mathrm{~mm} / \mathrm{min}$ ) in plano grinding. However for Pyrex glass, an additional feed of $2.5 \mathrm{~mm} / \mathrm{min}$ and depth of cut of $10 \mu \mathrm{m}$ were used. The wheel was dressed with $\mathrm{Al}_{2} \mathrm{O}_{3}$ bar (grade $\mathrm{Nr} \cdot 2$ ) each time before starting a new grinding condition. Surface roughness, form accuracy, and smoothness of all samples were analysed on a Form Talysurf while surface integrity was evaluated on scanning electron, atomic force and optical microscopes.

\section{Results and discussions}

\subsection{Aspheric surfaces on Ge and Si (Tan 1990)}

The resinoid-bonded wheel was superior for both $\mathrm{Ge}$ and $\mathrm{Si}$. It could be redressed and trued, and existing commercial sizes are available. The metal bonded wheel was made to our specifi- 


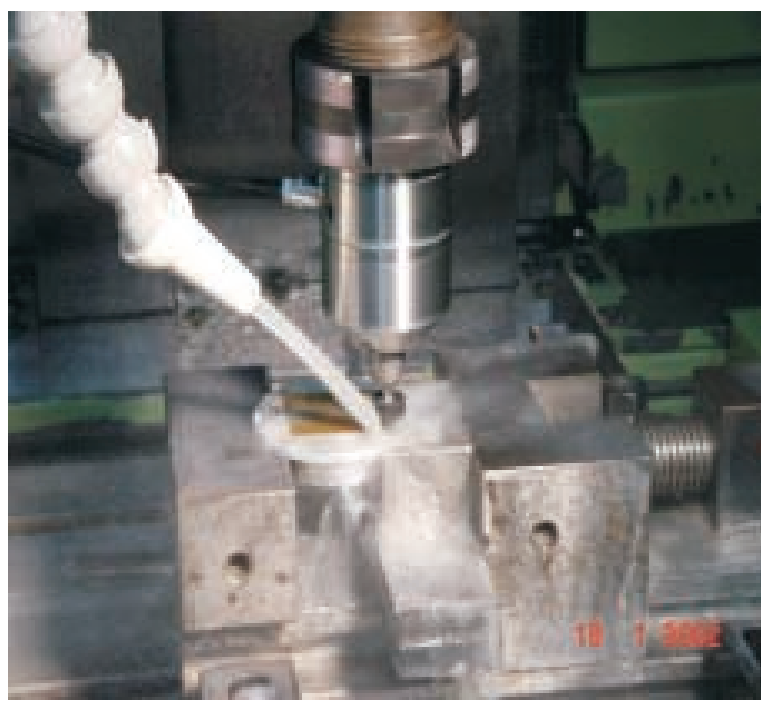

Figure 2. High-speed jig grinding of silicon and glass.

cations and had considerable run out $(0.279 \mathrm{~mm})$ which could not be corrected. Better surface roughness values were obtained with both wheels for $\mathrm{Si}$ (table 1). Si, however, was more difficult to polish and a lighter pressure had to be applied to prevent the felt from coming off. Thus, for the same time interval, Ge had a much better surface finish (table 1). Polishing improved the form accuracy with $\mathrm{Ge}$, but not with $\mathrm{Si}$ (table 1). Both ductile and fracture modes of material removal were observed with both $\mathrm{Si}$ and $\mathrm{Ge}$.

Figure 3 shows some amount of ductile streaks on silicon and figure 4 a massive amount of ductile streak on Ge. Better surface roughness, form accuracy, and smoothness can be obtained with a 5-axis CNC jig grinder, and also by dressing the grinding wheel by ductile mode as suggested by Miyashita (1988).

\subsection{Plano surfaces on silicon and glass (Izman 2003; Konneh 2003; Mon 2003)}

Results indicate that the surface roughness of precision ground Si improve with lower feed except in the case of the finest depth of cut of $5 \mathrm{~m}$ where higher feed rate improves the finish (figure 5). Ductile streaks also appear at higher feed rates (figure 6). Figure 7 is an AFM picture showing a mirror polished surface of ground Si that had ductile streaks.

Table 1. Average roughness and form accuracy after grinding $(G)$ and after polishing $(P)$.

\begin{tabular}{lccccc}
\hline & \multicolumn{2}{c}{$\mathrm{Ge}$} & & \multicolumn{2}{c}{$\mathrm{Si}$} \\
\cline { 2 - 3 } \cline { 5 - 6 } $\begin{array}{l}\text { Type of } \\
\text { grinding wheel }\end{array}$ & $\operatorname{Ra}(\mu \mathrm{m})$ & $\begin{array}{c}\text { Form accuracy } \\
(\mu \mathrm{m})\end{array}$ & & $R a(\mu \mathrm{m})$ & $\begin{array}{c}\text { Form accuracy } \\
(\mu \mathrm{m})\end{array}$ \\
\hline Metal-bonded $-G$ & 0.722 & 4.16 & & 0.583 & 6.03 \\
Metal-bonded $-P$ & 0.057 & 2.867 & & 0.123 & 6.490 \\
$\begin{array}{l}\text { Resinoid-bonded }-G \\
\text { Resinoid-bonded }-P\end{array}$ & 0.706 & 1.845 & & 0.123 & 1.898 \\
\hline
\end{tabular}



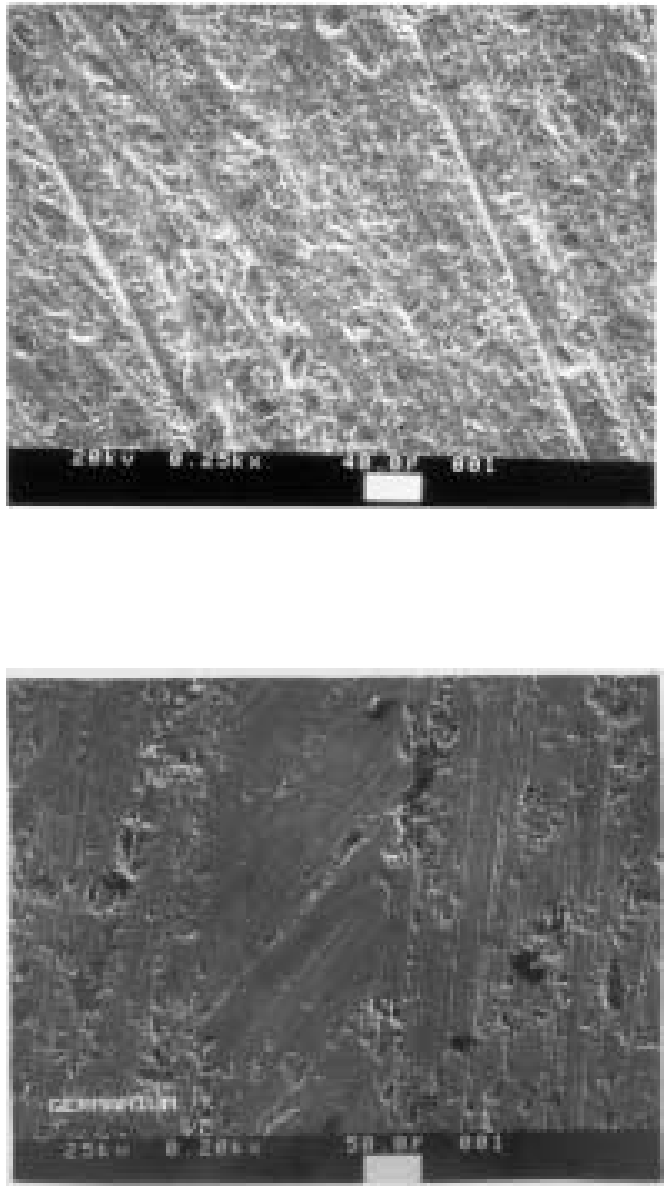

Surface Roughness vs Feed rate

(Grit D126- Monocrystalline Si)

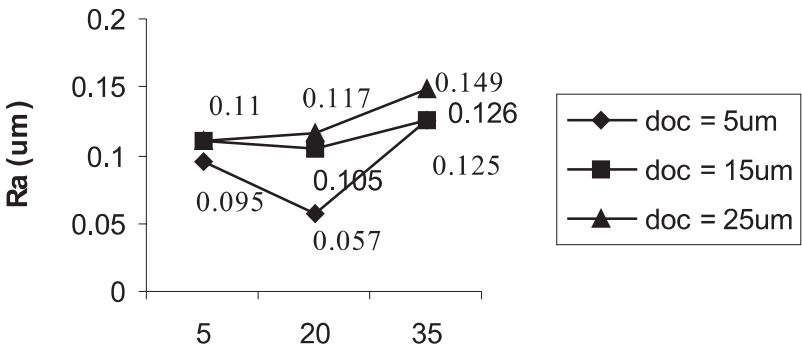

Feed rate $(\mathrm{mm} / \mathrm{min})$
Figure 3. Ductile streaks obtained on Si during aspheric generation.

Figure 4. Massive formation of ductile streaks on Ge during aspheric generation with a resinoid-bonded diamond wheel.
Figure 5. Surface roughness obtained when silicon dies were precision ground at different levels of depth of cut and feeds. 
(a)

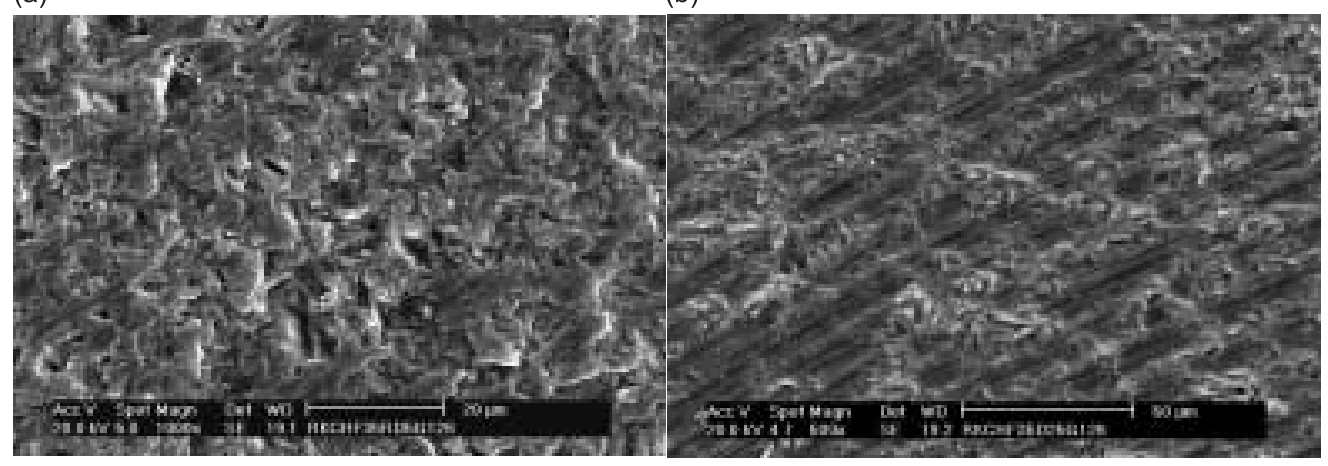

Figure 6. SEM pictures of ground Si. The surfaces consist of (a) microfractures and (b) grinding streaks.

Although the $25 \mu \mathrm{m}$ depth of cut gives relatively higher $R a$ values, ductile streaks are evident particularly at the $35 \mathrm{~mm} / \mathrm{min}$ feed. Getting partial ductile streaks on the ground surface is a much better deal than a good surface finish as the former from polishing experience of Venkatesh \& Zhong (1995) shows that saturation has taken place with the latter (figure 8).

Generally on BK7 glass, surface roughness improved with decrease of feed rate as shown in figure 9. As can be seen from the graph with the grit D126 size, depth of cut of $25 \mu \mathrm{m}$ provided the lowest Ra values at all levels of feed rate. Here again, it is seen that surfaces with ductile streaks obtained at a higher feed rate with higher surface roughness are better than the surface with the better surface finish as the latter has reached saturation condition (Venkatesh \& Zhong 1995).

Pyrex glass which has higher softening temperature $\left(1093^{\circ} \mathrm{K}\right)$ and lower linear expansion coefficient $\left(3.25 \times 10^{-6} / \mathrm{K}\right)$ than BK7 yielded ductile streaks at a lower depth of cut of $10 \mu \mathrm{m}$ at feeds of $2.5 \mathrm{~mm} / \mathrm{min}$ with a Ra value of $90 \mathrm{~nm}$ (figure 10). Figure $10 \mathrm{~b}$ shows diamond ground surfaces with 3 circular tracks (A, B, and C) of interest corresponding to the conical configuration of the diamond wheel shown in figure $10 \mathrm{a}$.

This wheel is traditionally used for internal grinding and a slight conicity of the wheel end is to provide grinding relief. When used as a surface grinding wheel with a vertical axis the conicity gets more pronounced. It was found that the adjacent tracks (B and C) have a larger amount of ductile streaks than the central track (A) as can be seen in figure 11. The polished surfaces have also proved that the adjacent tracks get polished more easily than the central track as shown in figure 12 .

\section{Conclusions}

During aspheric generation the following observations are made.

(1) Resinoid-bonded diamond wheel gave better results for both Si and Ge than metal bonded wheels.

(2) Germanium which is a much more expensive material than Silicon is easier to grind and polish. Unlike Si, Ge yields massive amounts of ductile mode streaks. 

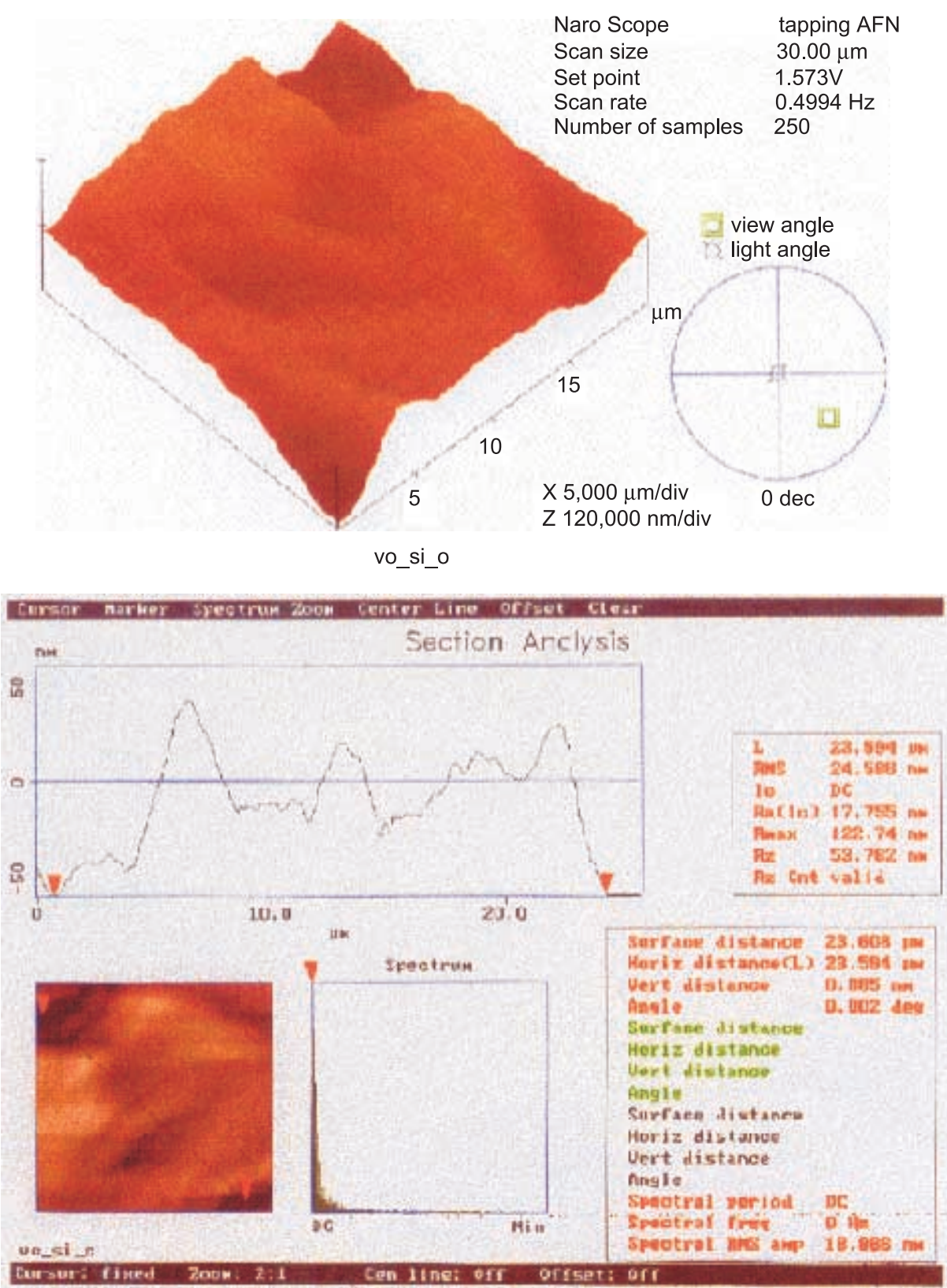

Figure 7. Atomic force micrographs of the polished silicon surface that was ground with ductile streaks gave a surface finish of $R a=17.755 \mathrm{~nm}$ and $R_{\max }=122.74 \mathrm{~nm}$. 


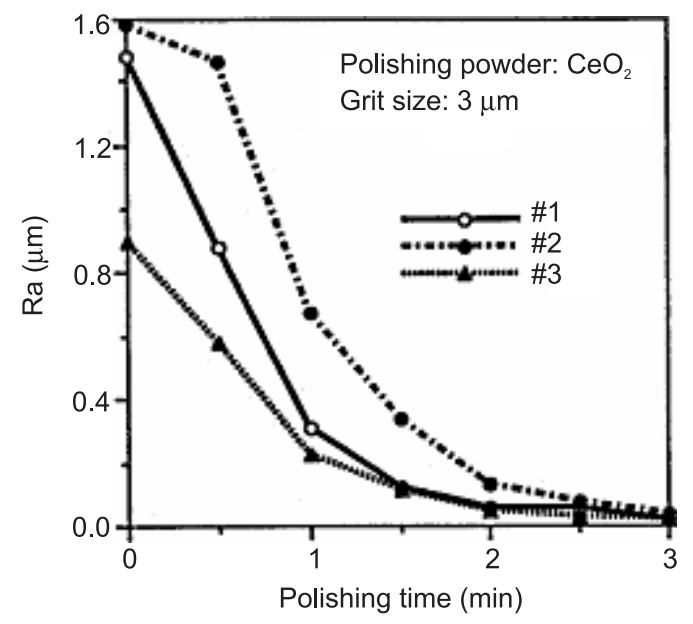

Figure 8. Roughness value versus polishing time. Curve \#1 with the largest amount of ductile streaks and maximum roughness achieved better surface finish faster than curve \#3 which has the best surface finish (Venkatesh \& Zhong 1995).

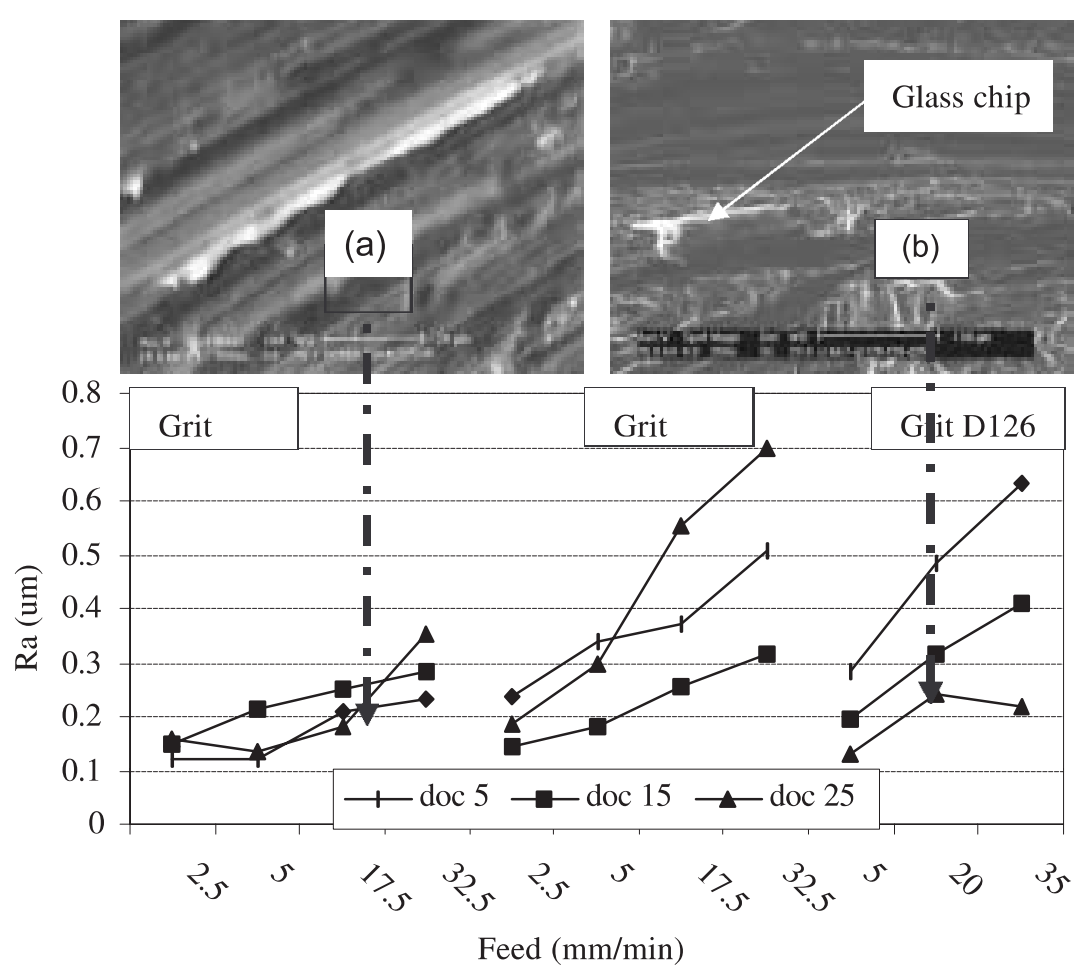

Figure 9. Surface roughness obtained by plano grinding with various grit sizes at different feeds and depth of cuts on BK7 glass. Partial ductile streaks are formed; (a) ploughing action takes place with the displaced material folding over (feed $22.5 \mathrm{~mm} / \mathrm{min}$, depth of cut $5 \mu \mathrm{m}$ ) and the other (b) where cutting action is evident with the formation of the chip (feed $20 \mathrm{~mm} / \mathrm{min}$, depth of cut $25 \mu \mathrm{m}$ ). 

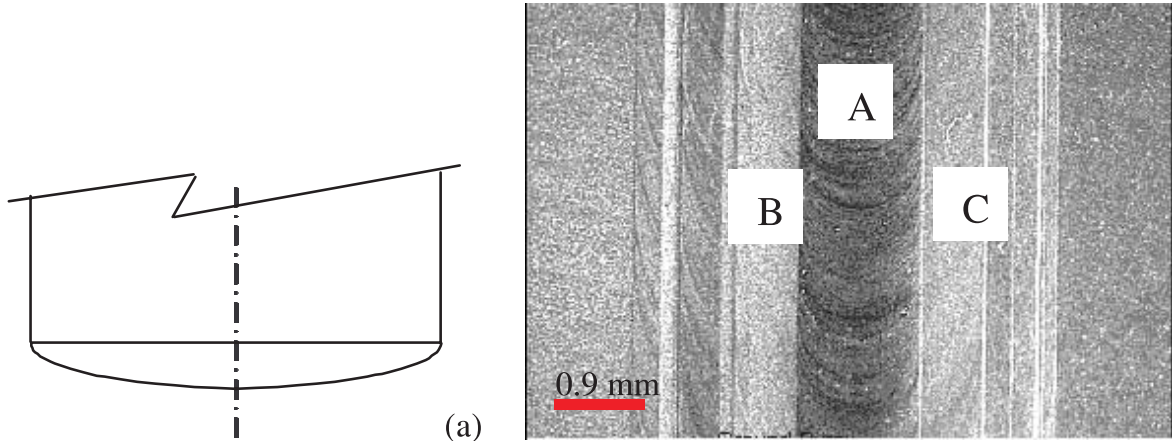

(b)

Figure 10. (a) Shows exaggerated conicity of grinding wheel (actual cone angle will be about $179 \cdot 4^{\circ}$ ). (b) The resulting grinding track.
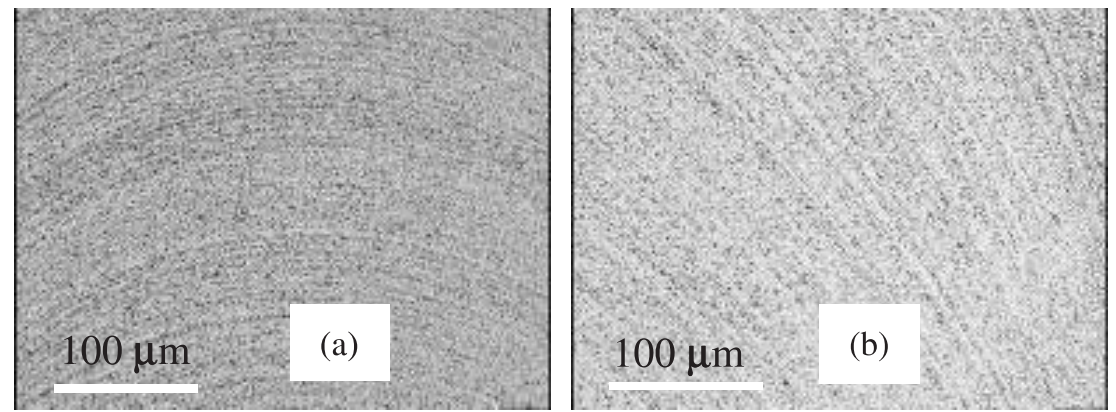

Figure 11. Optical micrographs of ground Pyrex glass surfaces of (a) the central track (A) and (b) the adjacent track (B) of figure 10 .

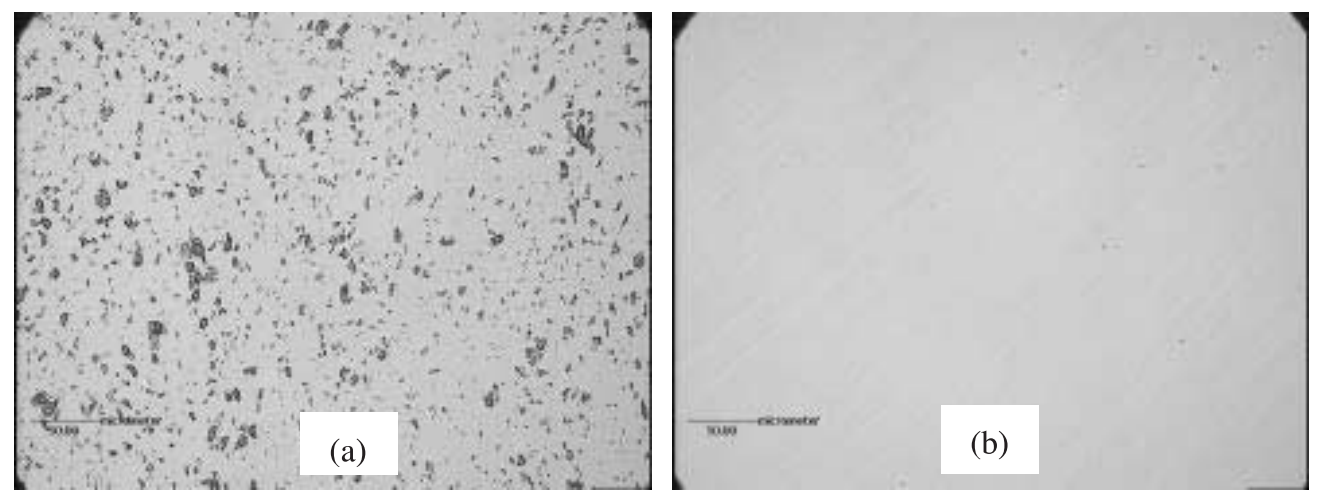

Figure 12. Optical micrographs of polished Pyrex glass surfaces of (a) the central track (A) and (b) the adjacent track. 
During high speed plano grinding, the results are as follows.

(1) Ductile mode grinding streaks occur at higher depth of cut with BK7 optical glass whereas with pyrex glass they occur at a lower depth of cut when a minimum feed is used in both cases.

(2) In the case of pyrex glass very fine depth of cut and feed are essential for getting ductile streaks over large areas, whereas in the case of BK7 such areas are scanty.

(3) With silicon considerable amount of ductile streaks are obtained at higher depths of cut just like BK7 glass.

(4) It has been observed with silicon, BK7 and pyrex glass that larger amount of ductile streaks is preferable to a ground surface with better finish in order to get an excellent polished surface finish. This is due to saturation effect observed in polishing curves.

(5) Two types of ductile streaks were observed: one with the cutting action accompanied by chip formation and the other by ploughing action with the displaced material folding over. The former type is desirable for defect free surfaces.

Sincere thanks are due to the Ministry of Science, Technology, and Environment, Malaysia for the IRPA Funding on Industrial Diamonds, Vote 72255 and to INTEL Malaysia, Penang for their research grant on Milling of Silicon Dies, Vote 68837.

\section{References}

Horne D F 1984 Optical production technology (Bristol: Adam Hilger)

Izman S 2003 Investigations into same aspects of partial ductile mode grinding of optical glass. Ph D thesis, Faculty of Mechanical Engineering, Universiti Teknologi Malaysia, Johor

Konneh M 2003 Experimental investigation on partial ductile mode grinding of silicon. $\mathrm{Ph} \mathrm{D}$ thesis Faculty of Mechanical Engineering, Universiti Teknologi Malaysia, Johor

Miyashita M 1988 Ultraprecision in manufacturing engineering (Berlin: Springer Verlag)

Mon T T 2003 Chemical mechanical polishing of optical glass subjected to partial ductile grinding. M Eng thesis, Faculty of Mechanical Engineering, Universiti Teknologi Malaysia, Johor

Tan C P 1990 Aspheric surface grinding and polishing of thermal imaging material. MS thesis, Tennessec Technological University, USA

Van Ligten R F Venkatesh V C 1985 Diamond grinding of aspheric surfaces on a CNC 4-axis machining centre. Ann. CIRP 34: 285-298

Van Ligten R F, Venkatesh V C 1986 Invention - Machine to make aspheric surfaces. Patent Disclosure, National University of Singapore

Venkatesh V C, Tan C P 1990 The generation of aspheric surfaces on thermal imaging materials on a 4-axis CNC machining center. Proc. Ame. Soc. Precision Engineer's Annual Meeting, Rochester, NY, pp 23-26

Venkatesh V C, Zhong Z 1995 Semi-ductile grinding and polishing of ophthalmic aspherics and spherics. Ann. CIRP 44: 339-342

Venkatesh V C, Izman S, Konneh M 2000 Ultra-precision and high precision turning and grinding of brittle materials. Proceedings Indo-Japanese Seminar (Hyderabad: Asian Academy of Sciences) pp 99-104 